\title{
Impact of depression on quality of life in people living with human T cell lymphotropic virus type 1 (HTLV-1) in Salvador, Brazil
}

\author{
Ana Verena Galvão-Castro • Ney Boa-Sorte • \\ Ramon Almeida Kruschewsky • Maria Fernanda Rios Grassi • \\ Bernardo Galvão-Castro
}

Accepted: 9 November 2011

(C) Springer Science+Business Media B.V. 2011

\begin{abstract}
Purpose A previous study found the prevalence of depression in HTLV-1-infected patients to be approximately $30 \%$, but few studies have attempted to correlate depression with quality of life (QOL) in these patients. The present study investigates the association between depression and QOL in people living with HTLV-1.

Methods A clinical-epidemiological questionnaire, the Mini International Neuropsychiatric Interview and the WHOQOLBref were applied to $88 \mathrm{HTLV}$-1-infected patients (32 with TSP/HAM) at the HTLV Center of the Bahiana School of Medicine and Public Health, Salvador, Brazil.

Results The prevalence of depression among people living with HTLV-1 was $34.1 \%$. Depression was significantly associated with a poor QOL in the physical, psychological, social relationship and environment domains, when controlling for other variables, such as gender, age, time of knowledge of serological diagnosis and presence of tropical spastic paraparesis/HTLV-1associated myelopathy (TSP/ HAM). Moreover, patients with TSP/HAM experienced a
\end{abstract}

Ana Verena Galvão-Castro and Ney Boa-Sorte contributed equally to this work.

This article is part of the Masters (MSc) thesis of Ana Verena GalvãoCastro of the Bahiana School of Medicine and Public Health, Postgraduate Course in Medicine and Human Health.

A. V. Galvão-Castro · N. Boa-Sorte - R. A. Kruschewsky ·

M. F. R. Grassi · B. Galvão-Castro ( $₫)$

Escola Bahiana de Medicina e Saúde Pública, Salvador, BA,

Brazil

e-mail: bgalvao@bahiana.edu.br

M. F. R. Grassi · B. Galvão-Castro

Escola Bahiana de Medicinae Saúde, Pública and Fundação

Oswaldo Cruz, Salvador, BA, Brazil reduction in their QOL in the physical, psychological and environment domains.

Conclusion Our results showed that depression negatively affects the quality of life of people living with HTLV-1, regardless of the presence of TSP/HAM. Since it is possible to improve a patient's QOL by treating depression, psychological evaluations are strongly recommended as a measure to integrate the treatment protocols of HTLV-1 intervention programs.

Keywords Human T-lymphotropic virus $1 \cdot$ Depression . Quality of life · HTLV-1-associated · Myelopathy

\section{Introduction}

HTLV-1 was the first retrovirus linked with human disease, and it is estimated that 20 million people are infected worldwide [1, 2]. HTLV-1 is endemic in Japan, the Caribbean, Central and South America, Equatorial Africa, the Middle East and Melanesia [3].

In Brazil, an estimated 2.5 million people are infected with HTLV-1 and the city of Salvador has the highest prevalence $(1.74 \%)$ in the country, with approximately 40,000 residents infected [4-6]. There is evidence that a broader spectrum of diseases is associated with HTLV-1 infection, including adult T-cell leukemia [7], tropical spastic paraparesis/HTLV-1-associated myelopathy (TSP/ HAM) [8, 9], HTLV-1-associated uveitis (HAU), infective dermatitis, arthritis, polymiositis, lymphocytic interstitial pneumonia [3, 4] and Keratoconjunctivitis sicca [10, 11].

TSP/HAM is characterized by a chronic and progressive demyelinating lesion characterized by paresthesia, dysesthesia, sensitive impairment in the lower members and progression to neurological disabilities ranged from 
moderate to a total incapacity to walk. The majority of patients with TSP/HAM have micturitional alterations including neurogenic bladder, as well as constipation, sexual dysfunction, loss of muscle strength and pain in the lower members [8, 9, 12, 13].

Depression $(30 \%)$ was the most commonly found mental disturbance among individuals infected by HTLV-1 [14-16]. Also, there is evidence that individuals living with HTLV-1 have a poor QOL [12, 17-19]. It has been demonstrated that depression negatively influences the QOL of patients, mainly those with chronic diseases [20]. This study showed, for the first time, that depression negatively impacts the QOL of patients living with HTLV-1, regardless of the presence of TSP/HAM.

\section{Materials and methods}

Study design, local and subjects

A cross-sectional study was carried out between March and November 2009 at the outpatient HTLV Center of the Bahiana School of Medicine and Public Health (EBMSP) in Salvador, the capital of the State of Bahia, located in northeastern Brazil. This city presents socioeconomic differences among its population of 3.5 million inhabitants of which roughly $80 \%$ are black or racially mixed with mainly African and Portuguese ancestry [21]. This center is open to the general public and has provided inter-disciplinary care services to 1,070 patients since 2002 , including general medical treatment, laboratory diagnosis, psychological counseling and physical therapy. At present, $50 \%$ of the HTLV-1-infected patients seen at the clinic are being regularly followed. The majority of these patients are women and approximately $30 \%$ have TSP/HAM.

HTLV-1 infection was assessed by ELISA (HTLV-1/ HTLV-2 Ab-Capture ELISA Test System, Ortho. Clinical Diagnostic Inc. Raritan, New Jersey, USA) and confirmed and discriminated between HTLV-1 and HTLV-2 using Western Blot (HTLV Blot 2.4; Genelabs, Singapore). TSP/ HAM was classified according to ascertainment level (possible, probable and definite) [13]. Ninety-five patients were selected consecutively and five of them were excluded by co-infection and two because they had a diagnosis of possible TSP/HAM. All volunteers, with age $\geq 18$, gave written informed consent before entering the research protocol. This study was approved by the Institutional Review Board of the EBMSP (Protocol number 122/2009).

Data collection procedures and instruments

Data collection was carried out by a single interviewer (AVG-C). The instruments used were as follows: (1) a standardized questionnaire, to assess sociodemographic, clinical and epidemiological data; (2) the Mini International Neuropsychiatric Interview, Brazilian Version 5.0 (M.I.N.I.), to estimate the presence of Current Major Depressive Episode (CMDE) and Recurrent Major Depressive Episode (RMDE). The instrument was validated in Brazil with a sensitivity and specificity of 86 and $84 \%$, respectively [22]. (3) The WHOQOL-Bref was also validated in Brazil, with satisfactory psychometric characteristics [23-25]. This instrument identifies four domains: physical, psychological, social relationships and environment [24]. It was applied using an interview form, due to the low education level of the subjects who may experience difficulties in comprehension.

Statistical analysis

With respect to continuous variables, mean values and standard deviation were considered and the $t$ test was used to compare QOL scores among the presence or absence of CMDE and/or RMDE, gender, place of residence, level of education, income and presence or absence of TSP/HAM. Analysis of Variance (ANOVA) testing was used to compare QOL scores among characteristics of marital status and time of diagnosis. Pearson's correlation coefficient was used to compare QOL scores and patient age. A multiple regression model was performed to calculated $\beta$ coefficients and examined the effects of each factor on the global and domain scores of patient QOL. A $P$-value $<0.05$ was considered to be statistically significant. All statistical analyses were performed using SPSS ${ }^{\circledR}$ version 17.0.

\section{Results}

The sample was composed of 88 individuals infected with HTLV-1 of whom 73 (83\%) were women. The age ranged from 18 to 87 years, with a mean (SD) age of 43.7(15.1) and a median age of the 42.0 years. The other socialdemographics characteristics were described in Table 1.

With respect to depression, 30 out of $88(34.1 \%)$ and 11 out of $88(12.5 \%)$ have had CMDE and RMDE, respectively. TSP/HAM was observed in 32 out of $88(36.4 \%)$ individuals (Table 2).

Under bivariate analysis, patients with TSP/HAM had significantly lower QOL scores in all domain categories with the exception of the environment domain that was not significantly lower when compared to asymptomatic individuals. CMDE negatively impact a patient's QOL score in every domain category, but RMDE was only significantly associated with lower QOL scores in the psychological domain (Table 2). Individuals who were aware of their serological diagnosis for longer periods of time had poorer 
Table 1 Scores of quality of life in 88 HTLV-1 individuals according to social, economic and demographic variables in Salvador, Brazil

\begin{tabular}{|c|c|c|c|c|c|c|}
\hline \multirow[t]{2}{*}{ Variables } & \multirow[t]{2}{*}{$\mathrm{N}(\%)$} & \multicolumn{5}{|c|}{ Domains of quality of life mean (SD) } \\
\hline & & Physical health & Psychological & Social relationship & Environment & Overall \\
\hline \multicolumn{7}{|l|}{ Gender } \\
\hline Female & $73(83.0)$ & $12.19(2.92)$ & $13.06(3.30)$ & $13.53(3.48)$ & $12.00(2.49)^{*}$ & $12.58(2.99)$ \\
\hline Male & $15(17.0)$ & $12.23(3.90)$ & $13.82(2.91)$ & $13,51(3,10)$ & $13,33(1.60)^{*}$ & $13.20(3.36)$ \\
\hline \multicolumn{7}{|l|}{ Residence } \\
\hline Salvador & $68(77.3)$ & $11.93(3.11)$ & $12.97(3.38)$ & $13.33(3.57)$ & $11.88(2.46)^{*}$ & $12.47(3.24)$ \\
\hline Others cities & $20(22.7)$ & $13.08(2.88)$ & $13.93(2.62)$ & $14.20(2.71)$ & $13.40(1.81)^{*}$ & $13.40(2.16)$ \\
\hline \multicolumn{7}{|l|}{ Education (years) } \\
\hline$<9$ & $39(44.3)$ & $12.19(3.62)$ & $12.75(3.86)$ & $13.47(3.63)$ & $11.85(2.50)$ & $12.31(3.42)$ \\
\hline$\geq 9$ & $49(55.7)$ & $12.20(2.61)$ & $13.54(2.63)$ & $13.58(3.24)$ & $12.53(2.32)$ & $12.98(2.71)$ \\
\hline \multicolumn{7}{|l|}{ Income (MW) } \\
\hline$<1$ & $31(35.2)$ & $12.28(3.29)$ & $13.01(3.60)$ & $12.82(3.70)$ & 12.10 (2.06) & $12.84(3.57)$ \\
\hline$\geq 1$ & $57(64.8)$ & $12.15(2.99)$ & $13.29(3.05)$ & $13.92(3.19)$ & 12.30 (2.59) & $12.60(2.75)$ \\
\hline \multicolumn{7}{|l|}{ Marital status } \\
\hline With partner & 43 (48.9) & $11.97(3.12)$ & $12.65(3.23)$ & 13.55 (3.99) & $11.92(2.41)$ & $12.65(3.14)$ \\
\hline Single & $24(27.3)$ & $12.54(3.39)$ & $13.39(3.52)$ & $12.72(3.05)$ & $12.85(2.32)$ & 13.08 \\
\hline Divorced/widower & $21(23.9)$ & $12.25(2.72)$ & $14.06(2.81)$ & $14.41(2.13)$ & $12.14(2.48)$ & $12.29(1.93)$ \\
\hline
\end{tabular}

$S D$ standard deviation; * $P<0.05 ; M W$ minimum monthly wage (=US\$220.38)

Table 2 Scores of quality of life in 88 HTLV-1 individuals according to time of serological diagnosis clinical diagnosis, time of diagnosis and psychological variables, in Salvador, Brazil

\begin{tabular}{|c|c|c|c|c|c|c|}
\hline \multirow[t]{2}{*}{ Variables } & \multirow[t]{2}{*}{$\mathrm{N}(\%)$} & \multicolumn{5}{|c|}{ Domains of quality of life mean (SD) } \\
\hline & & Physical health & Psychological & Social relationship & Environment & Overall \\
\hline \multicolumn{7}{|c|}{ Serological diagnosis (years) } \\
\hline$\leq 1$ & $18(20.5)$ & $13.17(2.78)^{* * *}$ & $13.93(2.78)$ & $14.30(2.41)$ & $13.33(2.16)^{* * *}$ & $14.33(2.40)^{* * *}$ \\
\hline $1-5$ & $41(46.6)$ & $12.64(2.83)^{* * *}$ & $13.48(3.03)$ & $13.72(3.31)$ & $12.54(2.06)^{* * * *}$ & $12.30(2.87)^{* * * *}$ \\
\hline$>5$ & $29(33.0)$ & $10.96(3.29)^{* * *}$ & $12.32(3.67)$ & $12.78(3.96)$ & $11.10(2.63)^{* * *}$ & $11.24(3.01)^{* * *}$ \\
\hline \multicolumn{7}{|l|}{ TSP/HAM } \\
\hline Absent & $56(63.6)$ & $13.24(2.60)^{* * * *}$ & $13.74(2.94)^{*}$ & $14.33(2.96)^{* *}$ & $12.58(2.14)$ & $13.43(2.87)^{* *}$ \\
\hline Present & $32(36.4)$ & $10.36(3.03)^{* * *}$ & $12.23(3.53)^{*}$ & $12.13(3.70)^{* *}$ & $11.61(2.74)$ & $11.38(2.94)^{* *}$ \\
\hline \multicolumn{7}{|l|}{ CMDE } \\
\hline Absent & $58(65.9)$ & $13.17(2.72)^{* * *}$ & $14.71(2.45)^{* * *}$ & $14.37(2.70)^{* *}$ & $12.77(2.07)^{* *}$ & $13.69(2.67)^{* * * *}$ \\
\hline Present & $30(34.1)$ & $10.30(2.88)^{* * * *}$ & $10.24(2.43)^{* * *}$ & $11.91(4.02)^{* *}$ & $11.18(2.69)^{* *}$ & $10.73(2.80)^{* * * *}$ \\
\hline \multicolumn{7}{|l|}{ RMDE } \\
\hline Absent & 77 (87.5) & $12.34(3.03)$ & $13.63(3.06)^{* * *}$ & $13.61(3.25)$ & $12.38(2.39)$ & $12.91(2.89)$ \\
\hline Present & $11(12.5)$ & $11.17(3.39)$ & $10.12(2.86)^{* * *}$ & $12.97(4.47)$ & $11.14(2.34)$ & $11.09(3.73)$ \\
\hline
\end{tabular}

$S D$ standard deviation, TSP/HAM tropical spastic paraparesis/HTLV-1-associated myelopathy, $C M D E$ current major depressive episode, $R M D E$ recurrent major depressive episode

* $P<0.05$; ** $P<0.01$; *** $P<0.001$

QOL scores in the physical and environment domains (Table 2). However, this finding was not observed when adjusted for gender, depression and the presence of TSP/ HAM (Table 3).

Multivariate analysis observed that CMDE and TSP/ HAM were significantly negatively associated with the physical domain (Table 3). Additionally, patients with
TSP/HAM had significantly lower QOL scores in the psychological and social relationship domains, after adjusting for gender, age, serological status and depression. The occurrence of a CMDE was strongly associated with the psychological $(\beta=-4.54 ; P<0.001)$, environment $(\beta=-1.19 ; P=0.025)$ and social relationship domains $(\beta=-2.45 ; P<0.001)$. 
Table 3 Multivariate linear regression coefficients $(\beta)$ and 95\% confidence intervals (95\% CI) of the association between depression and domains of Quality of Life (WHOQOL-bref) adjusting by TSP/HAM, age, gender and time of serological diagnosis, in Salvador, Brazil

\begin{tabular}{lllll}
\hline Variables & \multicolumn{1}{l}{ Domains of quality of live $(\beta$ coefficient) } \\
\cline { 2 - 6 } & $\begin{array}{l}\text { Physical } \\
\left.\text { (adjusted } \mathrm{r}^{2}=0.357\right)\end{array}$ & $\begin{array}{l}\text { Psychological } \\
\left.\text { (adjusted } \mathrm{r}^{2}=0.452\right)\end{array}$ & $\begin{array}{l}\text { Social relationship } \\
\left.\text { (adjusted } \mathrm{r}^{2}=0.165\right)\end{array}$ & $\begin{array}{l}\text { Environment } \\
\left.\text { (adjusted } \mathrm{r}^{2}=0.133\right)\end{array}$ \\
\hline Depression (present) & $-2.84(-3.99 \text { to }-1.68)^{* * *}$ & $-4.54(-5.66 \text { to }-3.42)^{* * *}$ & $-2.45(-3.90 \text { to }-1.00)^{* *}$ & $-1.20(-2.25 \text { to }-0.15)^{*}$ \\
Age (years) & $-0.01(-0.05$ to 0.03$)$ & $-0.02(-0.06$ to 0.01$)$ & $0.001(-0.05$ to 0.05$)$ & $0.001(-0.03$ to 0.03$)$ \\
Gender (male) & $-0.69(-2.14$ to 0.75$)$ & $-0.33(-1.73$ to 1.07$)$ & $-0.72(-2.53$ to 1.10$)$ & $1.10(-0.22$ to 2.41$)$ \\
TSP/HAM (present) & $-2.64(-3.79 \text { to }-1.49)^{* * *}$ & $-1.12(-2.24 \text { to }-0.01)^{*}$ & $-2.10(-3.55 \text { to }-0.65)^{* *}$ & $-0.75(-1.80$ to 0.29$)$ \\
Time of serological & $0.02(-1.33$ to 1.38$)$ & $-0.41(-1.73$ to 0.90$)$ & $0.003(-1.70$ to 1.70$)$ & $1.08(-0.15$ to 2.31$)$ \\
diagnoses ( $\leq 1$ year) & & & & \\
\hline
\end{tabular}

TSP/HAM tropical spastic paraparesis; * $P<0.05 ; * * P<0.01 ; * * * P<0.001$

\section{Discussion}

The present study found that about one-third of individuals infected with HTLV-1 had depression, which negatively impacted the QOL of these patients. The association between CMDE and the lowest scores found for QOL remained significant even when controlling for other variables such as gender, age, time of knowledge of serological diagnosis, as well as TSP/HAM diagnosis. These results suggest that people living with HTLV-1 have a poor QOL. Indeed, these individuals presented lower QOL scores in all domains in comparison to apparently healthy individuals who were evaluated in the validation process of the WHOQOL-Bref in Brazil [24, 25].

The observed prevalence $(34.1 \%)$ of depression was consistent with previous study conducted in Brazil [14-16]. Although, no control group was included, the authors believe that a higher frequency of depression can be found in individuals infected with HTLV-1 compared to the prevalence $(13.2 \%)$ of depression in the general population of Salvador [26]. The frequency of depression found in the present study was similar to rates observed in patients with chronic diseases $(35 \%)$ [20, 27], as well as in patients living with HIV $(20-45 \%)[28,29]$.

Moreover, $37.5 \%$ of individuals with TSP/HAM had depression, which confirms findings from a previous study [16]. The presence of TSP/HAM was also shown to have a significantly negative impact on scores in the physical, psychological and social relationship domains of QOL, corroborating previous results [19]. This was expected, due to the characteristically chronic and progressive nature of this disease [20]. In addition, it was observed that the QOL of individuals with TSP/HAM is mainly impaired with respect to the physical domain, functional capacity and pain [12, 19]. In addition, chronic pain has recently been associated with signs of anxiety and depression, thereby negatively affecting the QOL in patients with TSP/HAM [12]. Therefore, it is also important to evaluate the roles of functional capacity and pain with respect to the QOL of individuals infected by the HTLV-1.
Our data corroborate the notion that depression may be a pervasive variable in predicting a poor QOL [30]. When individuals feel frail and face the possibility of a loss of motor function, thereby severely compromising the fulfillment of daily activities, these conflicts represent difficult situations to resolve in solitude and may very well lead to the development of psychological disorders, including depression [31]. In addition, it is known that depression directly influences an individual's perception of their own QOL. Indeed, the intensity of the symptoms of depression has been shown to have a negative correlation with a poor self-rated state of health [32].

The high prevalence of depression may also be related to other biological factors. HTLV-1 induces a high amount of pro-inflammatory cytokines, such as TNF-alpha and IL6 [33]. Several studies indicated that increased circulating levels of these cytokines may play a role in the pathogenesis of depression [34-36].

The findings of this study should be interpreted with caution due to methodological limitations. As the present study was cross-sectional in design, it was not possible to establish a causal relationship between depression and QOL.

Since depression was observed to negatively impact the QOL of people living with HTLV-1, regardless of the presence of TSP/HAM, the authors strongly recommend that the assessment of depression and QOL be included in treatment protocols and caregiver guidelines for these individuals.

Acknowledgments We would like to thank Ms. Sonia Rangel, Mr. Noilson L. Gonçalves and Andris K. Walter for the recruitment of patients, technical assistance and English revision, respectively.

\section{References}

1. Poiesz, B. J., Ruscetti, F. W., Gazdar, A. F., Bunn, P. A., \& Minna, J. D. (1980). Gallo RC: Detection and isolation of type C retrovirus particles from fresh and cultured lymphocytes of a patient with cutaneous T-cell lymphoma. Proceedings of the 
National Academy of Sciences of the United States of America, 77, 7415-7419.

2. de Thé, G., Bomford, R. (1993). An HTLV-I vaccine: Why, how, for whom? AIDS Research and Human Retroviruses, 9, 381-386.

3. Hlela, C., Shepperd, S., Khumalo, N. P., \& Taylor, G. P. (2009). The prevalence of human T-cell lymphotropic virus type 1 in the general population is unknown. AIDS Reviews, 11, 205-214.

4. Carneiro-Proietti, A. B., Catalan-Soares, B., Proietti, F. A., \& Group GIH-IR. (2002). Human T cell lymphotropic viruses (HTLV-I/II) in South America: should it be a public health concern? Journal of Biomedical Science, 9, 587-595.

5. Galvão-Castro, B., Loures, L., Rodriques, L. G., Sereno, A., Ferreira Júnior, O. C., Franco, L. G., et al. (1997). Distribution of human T-lymphotropic virus type I among blood donors: a nationwide Brazilian study. Transfusion, 37, 242-243.

6. Dourado, I., Alcantara, L. C., Barreto, M. L., da Gloria Teixeira, M., \& Galvão-Castro, B. (2003). HTLV-I in the general population of Salvador, Brazil: a city with African ethnic and sociodemographic characteristics. Journal of Acquired Immune Deficiency Syndromes, 34, 527-531.

7. Yoshida, M., Miyoshi, I., \& Hinuma, Y. (1982). Isolation and characterization of retrovirus from cell lines of human adult T-cell leukemia and its implication in the disease. Proceedings of the National Academy of Sciences of the United States of America, 79, 2031-2035.

8. Gessain, A., Barin, F., Vernant, J. C., Gout, O., Maurs, L., Calender, A., et al. (1985). Antibodies to human T-lymphotropic virus type-I in patients with tropical spastic paraparesis. Lancet, 2, 407-410.

9. Osame, M., Izumo, S., Igata, A., Matsumoto, M., Matsumoto, T., Sonoda, S., et al. (1986). Blood transfusion and HTLV-I associated myelopathy. Lancet, 2, 104-105.

10. Merle, H., Smadja, D., Le Hoang, P., Bera, O., Cabre, P., Landau, M., et al. (1996). Ocular manifestations in patients with HTLV-I associated infection-a clinical study of 93 cases. Japanese Journal of Ophthalmology, 40, 260-270.

11. Castro-Lima Vargens, C., Grassi, M. F., Boa-Sorte, N., RathsamPinheiro, R. H., Olavarria, V. N., de Almeida Kruschewsky, R., et al. (2011).Keratoconjunctivitis sicca of human T cell lymphotropic virus type 1 (HTLV-1) infected individuals is associated with high levels of HTLV-1 proviral load. J Clin Virol.

12. Netto, E. C., \& Brites, C. (2011). Characteristics of chronic pain and its impact on quality of life of patients with HTLV-1-associated myelopathy/tropical spastic paraparesis (TSP/HAM). Clinical Journal of Pain, 27, 131-135.

13. De Castro-Costa, C. M., Araújo, A. Q., Barreto, M. M., Takayanagui, O. M., Sohler, M. P., da Silva, E. L., et al. (2006). Proposal for diagnostic criteria of tropical spastic paraparesis/ HTLV-I-associated myelopathy (TSP/HAM). AIDS Research and Human Retroviruses, 22, 931-935.

14. Galvão-Phileto, A., Pereira, I., Lima, N., Nunes, C., Seabra, A., Fereira, T., et al. (2006). Avaliação dos indicadores de saúde mental e do nível de depressão (ISMND) em indivíduos infectados por HTLV-1. Revista Da Sociedade Brasileira de Medicina Tropical, 39, 42.

15. Stumpf, B. P., Carneiro-Proietti, A. B., Proietti, F. A., Rocha, F. L., \& Group IHR. (2008). Higher rate of major depression among blood donor candidates infected with human t-cell lymphotropic virus type 1. International Journal of Psychiatry in Medicine, 38, 345-355.

16. Carvalho, A. G., Galvão-Phileto, A. V., Lima, N. S., Jesus, R. S., Galvão-Castro, B., \& Lima, M. G. (2009). Frequency of mental disturbances in HTLV-1 patients in the state of Bahia, Brazil. Brazilizian Journal of Infect Diseases, 13, 5-8.

17. Castro, N. M., Rodrigues, W., Freitas, D. M., Muniz, A., Oliveira, P., \& Carvalho, E. M. (2007). Urinary symptoms associated with human T-cell lymphotropic virus type I infection: evidence of urinary manifestations in large group of HTLV-I carriers. Urology, 69, 813-818.

18. Diniz, M. S., Feldner, P. C., Castro, R. A., Sartori, M. G., \& Girão, M. J. (2009). Impact of HTLV-I in quality of life and urogynecologic parameters of women with urinary incontinence. European Journal of Obstetrics, Gynecology, and Reproductive Biology, 147, 230-233.

19. Shublaq, M., Orsini, M., \& Puccioni-Sohler, M. (2011). Implications of TSP/HAM functional incapacity in the quality of life. Arquivos de neuro-psiquiatria, 69, 208-211.

20. Rocha, N. S., \& Fleck, M. P. (2010). Evaluation of quality of life in adults with chronic health conditions: the role of depressive symptoms. Revista brasileira de psiquiatria, 32, 119-124.

21. Azevêdo, E. S., Fortuna, C. M., Silva, K. M., Sousa, M. G., Machado, M. A., Lima, A. M., et al. (1982). Spread and diversity of human populations in Bahia, Brazil. Human Biology, 54, 329-341.

22. Amorim, P. (2000). Mini International Neuropsychiatric Interview (MINI): validação de entrevista breve para diagnóstico de transtornos mentais. Revista Brasileira de Psiquiatria, 22, 106-115.

23. Development of the World Health Organization. (1998). WHOQOL-BREF quality of life assessment. The WHOQOL Group. Psychological Medicine, 28, 551-558.

24. Fleck, M. P., Louzada, S., Xavier, M., Chachamovich, E., Vieira, G., Santos, L., et al. (2000). Application of the Portuguese version of the abbreviated instrument of quality life WHOQOL-bref. Revista de Saude Publica, 34, 178-183.

25. Berlim, M. T., Pavanello, D. P., Caldieraro, M. A., \& Fleck, M. P. (2005). Reliability and validity of the WHOQOL BREF in a sample of Brazilian outpatients with major depression. Quality of Life Research, 14, 561-564.

26. Almeida-Filho, N., Lessa, I., Magalhães, L., Araúho, M. J., Aquino, E., \& de Jesus, M. J. (2007). Co-occurrence patterns of anxiety, depression and alcohol use disorders. European Archives of Psychiatry and Clinical Neuroscience, 257, 423-431.

27. Fullerton, C., Florenzano, R., \& Acuña, J. (2000). Comorbidity of chronic diseases and psychiatric disorders among patients attending public primary care. Revista Medica de Chile, 128, 729-734.

28. Penzak, S. R., Reddy, Y. S., \& Grimsley, S. R. (2000). Depression in patients with HIV infection. American Society of HealthSystem Pharmacists, 57, 376-386, quiz 387-379.

29. Valente, S. M. (2003). Depression and HIV disease. Journal of Association of Nurses in AIDS Care, 14, 41-51.

30. Cruz, L. N., Fleck, M. P., \& Polanczyk, C. A. (2010). Depression as a determinant of quality of life in patients with chronic disease: data from Brazil. Social Psychiatry and Psychiatric Epidemiology, 45, 953-961.

31. Noble, J., Greene, H., \& Levinson, W. (2001). Textbook of Primary Care Medicine (3rd ed.). Philadelphia: Mosby.

32. Bonicatto, S. C., Dew, M. A., Zaratiegui, R., Lorenzo, L., \& Pecina, P. (2001). Adult outpatients with depression: worse quality of life than in other chronic medical diseases in Argentina. Social Science and Medicine, 52, 911-919.

33. Goncalves, D. U., Proietti, F. A., Barbosa-Stancioli, E. F., Martins, M. L., Ribas, J. G., Martins-Filho, O. A., et al. (2008). HTLV-1-associated myelopathy/tropical spastic paraparesis (TSP/HAM) inflammatory network. Inflamm Allergy Drug Targets, 7, 98-107.

34. Raison, C. L., Lowry, C. A., \& Rook, G. A. (2010). Inflammation, sanitation, and consternation: loss of contact with coevolved, tolerogenic microorganisms and the pathophysiology and treatment of major depression. Archives of General Psychiatry, 67, $1211-1224$ 
35. Dowlati, Y., Herrmann, N., Swardfager, W., Liu, H., Sham, L., Reim, E. K., et al. (2010). A meta-analysis of cytokines in major depression. Biological Psychiatry, 67, 446-457.
36. Schmidt, H. D., Shelton, R. C., \& Duman, R. S. (2011) Functional biomarkers of depression: diagnosis, treatment, and pathophysiology. Neuropsychopharmacology. 